\title{
The Integrity of Religious Believers
}

\author{
Paul Bou-Habib
}

Department of Government, University of Essex

\begin{abstract}
According to Cécile Laborde, persons with religious commitments that are incidentally burdened by generally applicable laws should, under certain circumstances, be provided with an exemption from those laws. Laborde's justification for this view is that religious commitments are a type of commitment with which a person must comply if she is to maintain her integrity. I argue that Laborde's account is insufficiently demanding in terms of the other-regarding attitudes it expects people to have before they can make claims to exemptions based on their integrity. The reason it is insufficiently demanding is that Laborde's account rests on what I call a 'non-moralised' view of integrity. I raise some criticisms of this view and defend the alternative, 'moralised' view of integrity, according to which the value of a religious person's integrity depends on whether the practice she wishes to perform complies with certain moral constraints.
\end{abstract}

Keywords: Laborde; religion; exemptions; integrity; sincerity

Cécile Laborde defends the view that persons with religious commitments that are incidentally burdened by generally applicable laws should, under certain circumstances, be provided with an exemption from those laws. For example, Orthodox Jews, who believe they have an obligation not to allow their body to be desecrated, may be entitled, under certain circumstances, to an exemption from a legal requirement to undergo post-mortem autopsies that would apply to other persons in the same circumstances. ${ }^{1}$ At the same time, Laborde does not believe that just any kind of commitment that is incidentally burdened by laws qualifies for legal exemption. If a committed body-builder doesn't want his body tampered with after his

\footnotetext{
${ }^{1}$ The example is discussed by Laborde (2017, p. 213). As Laborde points out, the original source of the example is Galston and Greenawalt (2008, p. 315).
} 
death, he will not, presumably, be exempt from an autopsy requirement that would typically apply in his kind of circumstance. ${ }^{2}$ The question that naturally arises is why committed body-builders shouldn't get the same treatment as Orthodox Jews. What's so special about a religious commitment?

The answer, according to Laborde, is that religious commitments are a type of commitment with which a person must comply if he is to maintain his integrity. When Orthodox Jews wish not to be subjected to an autopsy after their death, they wish for something in which their integrity is at stake. This isn't true for body-builders as well. Why not? Because integrity requires that an individual 'live in accordance with how she thinks she ought to live' (2017, p. 197). Body-builders, of course, do believe that they ought to shape and preserve their bodies in certain ways, but the 'ought' they thereby follow is just a hypothetical imperative - an 'ought' premised only on a preference they happen to hold. It isn't the categorical kind of 'ought' that Orthodox Jews believe they must follow when they demand an exemption from an autopsy requirement. To say this, however, isn't to imply that one must be religious in order to be bound by imperatives of a categorical nature. Laborde's integrity-based defence of religious exemptions doesn't imply that only religious persons can be entitled to exemptions: atheists with deep ethical or moral commitments also qualify for consideration. $^{3}$

\footnotetext{
${ }^{2}$ The body-builder example is my illustration of Laborde's view, no one that she provides herself.

${ }^{3}$ I use the term 'ethical' to refer to matters pertaining to the good life, and 'moral' to matters pertaining to what we owe to each other.
} 
I think the integrity of religious believers is a promising basis for why the law should, under certain circumstances, grant exemptions to religious commitments. ${ }^{4}$ But I want to raise some questions about how Laborde spells out the integrity-based argument for exemptions. These questions add up to the following, general point. Laborde's account may be too generous in the way in which it identifies the scope of commitments in which a person's integrity is implicated. In particular, I believe Laborde's account is insufficiently demanding in terms of the other-regarding attitudes it expects people to have before they can make claims to exemptions by appealing to their integrity. This is because on Laborde's account, while the value of integrity does not always trump the interests of others -and so does not support exemptions for religious people who wish to treat others indecently - a person's integrity can, at least, tell in favour of his being exempted from a requirement not to treat others indecently. I believe that this claim should be rejected and that we should endorse a 'moralised' account of integrity, according to which whether the value of a religious person's integrity is threatened at all in an exemption decision is something that depends on whether the practice he wishes to perform complies with certain moral constraints.

\section{Laborde's Non-Moralised Account of Integrity}

Laborde's account of religious exemptions employs a two-pronged test for determining whether a practice should be exempted from a generally applicable legal regulation. The first stage of the test assesses the value of the practice in question. Laborde puts the question at issue in the first stage as follows: '[w]hat is it about

\footnotetext{
${ }^{4}$ For other writers who have endorsed an integrity-based justification of religious exemption, see Bou-Habib (2006), Maclure and Taylor (2011), and Lenta (2016).
} 
religious claims that justifies the special concern exhibited in exemptions from general law?' To pass this first stage, a given practice must contain 'specific normative values that the law has reason to protect' (2017, p. 195). Once this first stage is passed, we next assess whether the law has adequate reason to refuse exempting the practice in question. I will concentrate on Laborde's explanation of the first stage of test. It is here that she invokes the idea of integrity. She believes that because the law has reason to refrain from undermining the integrity of persons, and because the integrity of religious persons depends on their being able to perform religious practices, the law has a pro tanto reason to exempt their religious practices from its otherwise applicable regulations.

For Laborde, a person lives with integrity if, and only if, that person's actions conform to that person's own religious convictions. When determining whether a religious claimant's integrity is at stake, courts must therefore follow what she calls a Thick Sincerity test (2017, p. 199). They must ask of a given religious practice under consideration whether it is demanded by a religious claimant's religion as that religion is interpreted not by other members of his religious community, but by the claimant himself. When Laborde qualifies the kind of sincerity that is necessary as thick sincerity, she means that a religious claimant's convictions must view the practice the claimant wishes to perform as having a certain categorical status. The relevant practice must be non-trivial - i.e. 'not simply to a whim, preference or un-reflected prejudice' and important - i.e. it 'not simply a peripheral, incidental or occasional commitment.' (2017, p. 200)

Acting in conformity with their own religious convictions, then, is a necessary condition for persons to live with integrity. The question I want to discuss is whether this condition is sufficient as well. On this question, Laborde is not fully clear, but the 
most reasonable reading of her account is that conformity of action with conviction is, indeed, sufficient. ${ }^{5}$ This is made clear, in particular, in Laborde's discussion of why there may not be a religious exemption for infant sacrifice: 'One could suggest,' she writes, 'that morally abhorrent claims are flatly incompatible with the pursuit of integrity. People of integrity cannot do abhorrent things...' (2017, p. 201). This line of argument is one that she explicitly rejects because she believes that a sincere commitment to performing infant sacrifice can indeed be what she calls an 'integrityprotecting commitment' (2017, p. 202). Laborde obviously does not believe that infant sacrifice should be accommodated, but her reason for denying that it should be accommodated is that it is morally abhorrent, not that the integrity of the practitioner of infant sacrifice is not at stake in his performing it.

Because it does not build moral constraints into the definition of integrity, Laborde's account of integrity is a 'non-moralised' account of integrity. The contrasting account, which holds that the value of integrity depends on the practitioner's complying with certain moral constraints, is a 'moralised' account. Before discussing a problem for the non-moralised account of integrity, it may be helpful to note how the two accounts differ in their practical implications.

\footnotetext{
${ }^{5}$ Laborde implies, at one point, that an additional condition is necessary for integrity, which she calls Thin Acceptability, and by which she means that a practice must meet certain very basic criteria of moral decency. She asks, "which test should judges use to assess integrity? I set out two tests, which I call Thick Sincerity and Thin Acceptability' (2017, p. 199). But, as I now explain, if we attend to what Laborde explicitly says elsewhere, it is clear that she does not, in fact, regard Thin Acceptability as a test of integrity.
} 
Both accounts agree on the thick sincerity test, but they imply that courts should follow different procedures once they have established that the religious claimant meets that test. On the moralised account, courts must ask whether the religious practice in question meets certain moral constraints. If it does not, the religious person's claim lacks the requisite standing, since his integrity is not at stake, and courts can conclude that there is no integrity-based case for exemption. If, by contrast, the practice does meet certain moral constraints, the religious person's integrity is at stake, and the moralised account requires courts to proceed to a second stage of reasoning in which they ask whether the interests protected by the law are sufficiently weighty to justify overriding the claimant's integrity. The non-moralised account recommends a different procedure. Once the religious claimant's thick sincerity has been established, courts must proceed straight to the second stage, where they balance interests. The non-moralised account recommends that courts skip over the first stage of the moralised account because it says that we must credit all religious claimants with integrity. Laborde's version of the non-moralised accounts has a twist, insofar as it builds in an exception to this fast-track procedure: if the practice under consideration is morally abhorrent (e.g. infant sacrifice) we don't fast-track to the balancing stage, but issue an immediate denial of exemption. Whether there is a difference between the practical implications of the moralised and non-moralised accounts of integrity thus depends on how a proponent of the moralised account defines the 'moral constraints' that a religious practice must meet in order to for the integrity of the claimant to be at stake and how Laborde defines the category of the 'non-abhorrent'. If these two terms are defined in the same way, then there is no 
practical difference between the accounts. They would allow the same practices to proceed to the second stage of deliberation, where interests are balanced. ${ }^{6}$

\section{A Problem for the Non-Moralised Account}

I would now like to raise a problem for the non-moralised accounts of integrity.

Stated in the most general terms, the problem is that a non-moralised account does not adequately serve the purpose that an account of the basis of a religious exemption must serve. Such an account must show us that the practices that merit religious exemption are, in some way, valuable or worthy of our respect. An account of religious exemptions that appeals to integrity aims to shows us just this: it says that religious practices are valuable or worthy of respect because they enable persons to achieve conformity between their actions and their deepest convictions about how they must live. But I believe that the capacity of an integrity-based account to show us that religious practices are valuable or worthy of respect, and thus justifiably exempted from regulation, is undermined if that account characterizes integrity in non-moralised terms.

Consider, again, the example of infant sacrifice. Laborde believes that this practice, even though it is abhorrent, is one that a person's integrity may require him to perform. The trouble is that integrity, in this case, doesn't seem valuable or respectworthy at all. Our attitude towards another person's conviction that he must perform infant sacrifice is not one of respect that, in the absence of counter-veiling considerations, would prompt us to act with forbearance and accommodation. The

\footnotetext{
${ }^{6}$ Although the moralised and non-moralised accounts support the same judgements in these cases, and so appealing to these cases does not settle the case in favour of the moralised account, my arguments in what follows aim to do just that.
} 
conviction that he must sacrifice an infant seems rather to resemble a horrible psychological affliction for him. (If acted upon, it would of course also be a profound evil for the infant who is sacrificed. $)^{7}$

Laborde is aware of this problem. But I am not sure her reply to it succeeds. She writes:

If individuals are sincerely committed to the pursuit of a wicked cause, they can still be said to act with integrity: it simply means that integrity is one value among others, not the paramount or overriding value... So it is not correct to say, as some have, that because individuals possessing personal integrity may be wicked, integrity is without value. There is value in people pursuing the subjectively-held projects and commitments that are central to their life and worldview - but the pursuit of integrity cannot justify the performance of morally abhorrent actions (2017, p. 202).

Laborde's reasoning is, I take it, the following. We want to deny, of course, that someone who wishes to perform infant sacrifice should get an exemption; we could deny this, while recognizing that this person's integrity requires him to perform infant sacrifice, by denying that integrity matters. But, Laborde notes that we need not deny that integrity matters in order to deny that this person should receive an exemption. We need only assert that there is some superior value that outweighs the value of his integrity (such as the life of the infant). While I agree that the position Laborde endorses here can deliver the desired conclusion regarding whether exemptions

\footnotetext{
${ }^{7}$ For another source of skepticism of the view that compliance with deep conviction is valuable or respect-worthy as such, see Koppelman (2009).
} 
should be granted, I do not think it is fully satisfactory. Laborde's position only answers one challenge raised by the example of a person whose religion requires him to perform clearly morally impermissible acts, i.e. that attributing value to integrity must be mistaken because it compels us to exempt evil actions (e.g. infant sacrifice). ${ }^{8}$ It does not answer a different challenge that the example of such a person raises for a defence of religious accommodation that appeals to integrity, namely this: attributing value to integrity must be mistaken because there is nothing valuable in someone's performing infant-sacrifice - not even the sheer fact of his complying with his conviction. That objection remains, and the worry that it generates thus remains as well, namely that integrity is just not valuable as such.

I think that objection is powerful. Although it raises complex issues that I cannot aim to settle here, let me make two brief suggestions in support of it. First, we can test our intuitions by imagining a scenario in which a person manages to conform to his wicked convictions, but without bringing about horrible consequences. Suppose, he sincerely believes he must press a button that causes infant sacrifice by electrocution, but that when he presses the button, the system malfunctions and the infant survives. How should we react to this scenario? It seems odd to think of it as a happy scenario (at least a person has acted in conformity with his convictions!). The more natural reaction is that there is nothing respect-worthy or valuable in what he has done, and that, if anything, he shows signs of a deep psychological affliction that we should try to help him overcome.

The second point is that we can question the examples given in favor of the non-moralised value of integrity. A famous example from Bernard Williams, which

\footnotetext{
${ }^{8}$ This is the version of the objection that Koppelman raises. See (2009, p. 222)
} 
Laborde, following Lenta, cites (2017, p. 202), is 'the fanatical Nazi who refused bribes which he was offered to save Jews'. ${ }^{9}$ The Nazi, some might say, possesses a valuable kind of integrity, even if the value of his remaining corruption-free (by refusing bribes) is vastly outweighed by the importance of saving Jews. My reaction is that it is only semantically apt to say of the Nazi that he possesses integrity and that there is nothing valuable or respect-worthy to be found in his conduct. In complying with his moral conviction that he must avoid corruption, the Nazi displays an inability to adjust his moral priorities to the overwhelmingly more important cause of saving innocent lives, and this evinces a profound insensitivity to the suffering of innocent people.

\section{Laborde's Objections to the Moralised Account}

That the non-moralised account of integrity is not entirely problem-free does not, of course, settle the case in favour of the moralised account. We first need to consider the problems the latter account might face. As I noted earlier, Laborde considers and rejects the moralised account. Let me now examine two objections that Laborde raises against the moralised account of integrity.

(a) The subjective theory of religious freedom. Laborde states the first objection briefly as follows: the moralised account of integrity 'is not compatible with a subjective theory of freedom of religion' (2017, p. 202). By a 'subjective theory of freedom of religion', Laborde means a theory 'according to which only individuals not the state, nor collective religious authorities - are entitled to determine what is the correct interpretation of religious, or more broadly moral, demands on them' (2017, p. $63)$.

\footnotetext{
${ }^{9}$ The quote is from Lenta (2016, p. 254).
} 
To assess this objection, we should distinguish two different dimensions of a given practice about which a theory of religious freedom might be subjective - i.e. dimensions of that practice with regard to which we should defer to the beliefs of the religious claimant. A subjective theory of freedom of religion may require deference to the religious claimant's beliefs about whether a given practice is, firstly, a religious demand for him, or it may require, secondly, that we defer to a claimant's beliefs about whether the given practice that his religion demands of him is valuable or respect-worthy.

I agree with Laborde that we should endorse the first version of the subjective theory. Courts should not defer to persons other than the religious claimant himself when deciding whether to accept his claim that a given practice is a religious demand for him. (Courts need not, of course, just take a person at his word about this - it may be reasonable for courts to assess his sincerity by asking questions, for example, about the steadfastness of his past commitment to honoring the religious demand in question.) However, the moralised account is compatible with this first version of the subjective theory. According to the moralised account, the value of integrity is limited to the performance of certain kinds of practices, those which are constrained by certain moral criteria. Provided that the practice the religious claimant wishes to perform meets those criteria, the moralised account can recommend that the court proceed straight to the balancing stage, without first asking whether authority figures within the claimant's community accept that the practice is actually required by his religion. So whether or not courts should defer to the claimant or authority figures within his community about that issue isn't something over which the moralised and non-moralised accounts of integrity disagree.

The moralised account of integrity is incompatible, however, with the second 
version of the subjective theory of religious freedom identified above, according to which courts must defer to the religious claimant about whether engaging in a given practice is valuable or respect-worthy. By insisting that the practice must meet certain moral criteria before the claimant's integrity can be said to be at stake, the moralised account is, in effect, insisting that it is insufficient that the claimant himself regard the practice as valuable or respect-worthy. However, Laborde is not explicit about why its being inconsistent with the second version of the subjective theory of religious freedom would be a problem for the moralised account. ${ }^{10}$ But she may implicitly have in mind the following problem of incoherence. The reason we have for insisting that the religious claimant himself, and not authority figures within his community, must be allowed to settle whether a practice is a religious demand for him, also seems to justify that he must be allowed to settle whether that practice is valuable or respectworthy in a way necessary for his integrity to be at stake. After all, if he should be recognized as a source of religious conviction who is independent from the authority figures within his community, should he not also be recognized as independent from the wider political community - represented by the court - in determining what practices are valuable or respect-worthy? So, once we endorse the first version of the subjective theory - as I agree, with Laborde, we must - we may seem committed to endorsing the second version, too, and hence, on grounds of coherence, to rejecting the moralised account of integrity.

I don't think that's correct. To say, as the moralised account can and should

\footnotetext{
${ }^{10}$ Laborde may not think that this is a problem for the moralised account. She may think the problem with the account is only that it is inconsistent with the first version of the subjective theory of religious freedom. But, as I just pointed out, I don't think it is.
} 
say, that a religious claimant should be allowed to settle what counts as a religious demand for him does not commit a proponent of the moralised account to also saying that the religious claimant must be able to settle whether the practice he wishes to perform meets the moral constraints with which it must comply in order for his integrity to be at stake. That we should recognize each other's independence within the sphere permitted by moral constraints does not imply that we should recognize each other's independence in setting the moral constraints themselves. It is not incoherent, therefore, for courts to insist that a religious claimant must be independent from authority figures within his community, while insisting that he may not also settle the moral constraints that practices must meet before the courts must acknowledge that their exercise is a matter for his integrity.

(b) Reasonable disagreement. Laborde's second main objection to the moralised account is implicit in how she characterizes the advantage that she believes the non-moralised account of integrity has over the moralised account. One advantage of not moralising integrity, she explains, is that it 'allows us to take seriously reasonable disagreement about liberal justice' (2017, p. 203). It does this because it allows courts to consider awarding exemptions to claims, which, while not morally abhorrent, are nevertheless, 'morally ambivalent'. These are claims 'that can be fitted into one or other recognizably liberal conception of justice', for example a claim to ‘inflict mild corporal punishment on one’s children’ (2017, p. 203). Because Laborde's non-moralised account of integrity allows that religious claimants can live with integrity when performing practices that not all recognize as morally acceptable, it takes seriously the fact that citizens can reasonable disagree about justice and the good life.

The implicit objection against the moralised account, I take it, is that it fails to 
do this. Because it holds that claims to exemption turn on whether the practices in question meet certain moral constraints, the moralised account implies that courts should enter into a moral evaluation of, say, mild corporal punishment for children and, if they conclude that the practice fails certain moral constraints, deny that parents who wish to perform this practice have integrity at stake. But this does not take seriously the fact that people can reasonably disagree about the moral acceptability of mild corporate punishment for children.

I do not think that the concern that courts - and the political community, more generally - should take seriously reasonable disagreement is relevant for whether courts must adopt a moralised or non-moralised account of integrity. Consider how courts would have to proceed if they adopted a non-moralised account. After allowing that the integrity of parents who believe they must inflict mild corporate punishment on religious grounds is at stake over whether they can perform that practice, they would have to assess whether the interests protected by the law justify denying the exemption in question. It is hard to see how, in doing this, a court would be doing anything substantively different from what the moralised account says it must do. Suppose a court concludes that the child's interests in avoiding pain and psychological trauma are too great to justify allowing parents to inflict mild corporal punishment, even if the parents hold deep convictions that they must. It would seem untruthful of a court to communicate the verdict as follows: 'We think the trauma to your children is too great to justify your doing this even if your integrity is at stake, but we are not saying that your doing it would be morally unacceptable.' Surely that is what the court is saying. The non-moralised account thus seems to allow the court to override the parents' view about the moral status of mild corporal punishment on the basis of its own moral verdict about that matter. It only does this at a different stage of 
deliberation from when it would do it if it proceeded on the basis of the moralized account. So it is difficult to see the sense in which courts, by following the nonmoralised account, would take reasonable disagreement any more seriously than they would were they to follow the moralised account.

\section{Integrity as Responsiveness}

I would now like to say something more foundational in support of the moralised account. My point of departure is the suggestion that it seems mistaken to think that the value we are trying to capture with the term 'integrity' should turn only on a fit between actions and deep conviction. Consider the following bizarre example:

Hypnotized homophobia. Henry has been hypnotized into holding a deep conviction that his God requires him to act in ways that express condemnation of homosexuality. Acting on this belief, he refuses to let out his property to a homosexual couple.

The question is whether Henry's integrity is at stake over the issue of whether he should be exempted from a generally applicable prohibition against discrimination on grounds of sexual orientation. Now, if all that mattered for his integrity were that he acts in line with his deep religious conviction, we would have to answer, 'yes'. But this seems like the wrong answer. Whatever it is whose value we are trying to capture with the term, ‘integrity', it doesn't seem present in Henry's case. ${ }^{11}$

\footnotetext{
${ }^{11}$ I am here adapting a version of an objection to the so-called 'hierarchical' account of autonomy raised by Mele (2001, pp. 147-8). According to the hierarchical account, it is sufficient for autonomous action that the agent's first-order desire to perform that
} 
What's missing? As well as consisting of enactment - i.e. of pressing conviction into action, integrity consists of responsiveness - of one's trying to figure out how one must live according to some standard or standards of ultimate value that one regards as having authority over oneself. To say something more specific about what such responsiveness might consist in, it is helpful to consider what it is we tend to regard as valuable or respect-worthy in straightforward cases of persons who act with integrity, for example a case in which officials resist strong pressure to disregard the interests of vulnerable people. What we admire about these officials, and what we name with the word 'integrity', is the fact that they are not allowing themselves to be swayed by considerations by which they ought not to be swayed. Integrity seems to consist, in other words, of a certain kind of resoluteness, a strong disposition to insulate oneself from considerations by which one should not, ideally, be affected, or, put more positively, to render oneself sensitive to the considerations that genuinely matter (or, in other words, that matter from an objective point of view). Drawing on this idea, we could say that integrity consists of forming and sustaining one's convictions in a way that is consistent with the most basic demands of justice, such as, for example, the demand that we respect the dignity of all persons. ${ }^{12}$

Why exactly would construing integrity in this way imply a moralised account of integrity - i.e. an account that sets moral constraints to the kinds of practices that should be considered as implicating a religious claimant's integrity? If the value of action is endorsed, in some way, by a second-order volition. See Frankfurt (1988, pp. 12-25). As Mele points out, however, how the second-order volition itself came about also seems relevant for autonomous action. See also Chrisman (1991).

${ }^{12}$ I am grateful to an anonymous referee for helping me to formulate this view more precisely. 
integrity consist in our good faith efforts at being responsive to the most basic demands of justice, then a relevant question about any given practice under consideration is whether the claimant's conviction that he must perform it is one that he could have formed, and could plausibly be sustaining, out of a good faith effort to comply with the most basic demands of justice. For example, there is overwhelming reason to suspect that a person who wishes to perform infant sacrifice has failed to form that conviction in a manner that is sensitive to the dignity of the infant he wishes to sacrifice. We should therefore conclude that there is no integrity at stake, here, because this person has not tried to constrain himself by the most basic demands of justice.

Infant sacrifice, of course, is an easy example with which to illustrate the plausibility of an account. So let's take a more controversial example that involves a religious person who is hostile to homosexuals but who, unlike Henry, has not been hypnotised into that hostility. In my view, we may have good enough reason to suspect of some religious people who manifest hostile attitudes towards homosexuals that they do not sustain those attitudes from a good faith effort at being responsive to the most basic demands of justice. For example, a court might establish that a particular religious claimant merely wishes to manifest homophobic prejudice (as opposed to a belief formed in good faith, that he must dissociate from homosexuals), say, by obtaining evidence that this claimant has regularly displayed hostile behaviour towards homosexuals in other contexts, where such hostile behaviour is not actually warranted by his religious beliefs (even as he himself would explain those beliefs). This evidence might lead the court to the conclusion that his anti-homosexual religious beliefs cannot be plausibly seen as a result of his taking seriously, among other considerations, the fundamental idea, which the court regards as objectively 
true, that all human beings have dignity. This doesn't mean that courts should disqualify all anti-homosexual religious beliefs as incompatible with integrity. Some religious claimants with anti-homosexual beliefs may well be able to demonstrate that they have taken seriously the idea that all human beings have dignity and their integrity may well be at stake, then, in whether or not they can disassociate from homosexuals. The point I am making is that we should not automatically assume that all anti-homosexual religious beliefs are compatible with the integrity of the religious believer.

One challenge for this way of thinking about the value of integrity is that we disagree about the objective moral constraints that courts should expect religious claimants to take seriously. That is certainly true, but the moral constraints that courts should insist upon need not be constraints over which people can reasonably disagree, but could be restricted to those over which people cannot reasonably disagree, such as the idea that all human beings have dignity.

A deeper challenge, which, for lack of space I can only register here, is this: one may think that it is sufficient for integrity that a person form and sustain his convictions in response to considerations that he thinks matter rather than considerations that objectively matter. My inclination is to deny this, and to assert that integrity is a kind of success that we achieve one when we strive, in good faith, to respond to the considerations that objectively matter in how we live our lives. A person who believes he must sacrifice an infant is someone who fails in this regard, either because he is not sustaining his beliefs in good faith, of, if he is, because he lacks a basic competence to appreciate the worth of the infant. And it is also my inclination to say that less extreme forms of indecency, such as some forms of homophobic religiosity, can also be failures in this regard. But much more needs to be 
said, of course, in support of this inclination, if we are to fully spell out the basis for the moralised account of integrity.

Let me conclude with a suggestion about why the difference between the moralised and non-moralised account of integrity matters. As I noted earlier, it is possible that the two accounts differ very little from each other, if at all, in their practical implications. Still, the moralised account tells us something that the nonmoralised does not, namely, that we should not recognize it as in any way valuable and neither should our political institutions, including our courts - that some members of our political community wish to comply with convictions that fail to show a certain basic consideration for others. That difference is important because we owe it to those to whom gross moral insensitivity is shown not to sanctify that insensitivity. But it is important also for another reason. Refusing to recognise as valuable a person's compliance with his own gross moral insensitivity is something that we owe also to that person himself, at least if he is able to do better. It expresses to him that we expect him to be, and regard him as capable of being, a full member of our moral community.

\section{References}

Bou-Habib, P., 2006. A Theory of Religious Accommodation. Journal of Applied Philosophy, 23 (1), 109-126.

Christman, J., 1991. Autonomy and Personal History. Canadian Journal of Philosophy. 21 (1), 1-24.

Laborde, C., 2017. Liberalism's Religion, Cambridge, MA: Harvard University Press.

Frankfurt, H., 1988. The Importance of What We Care About, Cambridge: Cambridge University Press.

Galston, W. and Greenawalt, K., 2008. Religion and the Constitution, Princeton: 
Princeton University Press.

Koppelman, A. 2009. Conscience, Volitional Necessity, and Religious Exemptions. Legal Theory, 15 (2), 215-244.

Lenta, P., 2016. Freedom of Conscience and the Value of Personal Integrity'. Ratio Juris, 29 (2), 246-263.

Maclure, J. Taylor, C., 2011. Secularism and Freedom of Conscience, Cambridge, MA: Harvard University Press.

Mele, A., 2001. Autonomous Agents: From Self-Control to Autonomy, New York and Oxford: Oxford University Press 